\title{
Scabies Knowledge Among Undergraduate Nursing Students in China: A Questionnaire Survey
}

\author{
Nan Liu', Yuchun Bai', Xing Li', Yanfei Zhang ${ }^{2}$ \\ 'College of Public Health of Xi'an FanYi University, Xian, Shaanxi Province, People's Republic of China; ${ }^{2}$ Department of Dermatology, The Second \\ Affiliated Hospital of Xi'an Jiaotong University, Xian, Shaanxi Province, People's Republic of China \\ Correspondence: Yanfei Zhang, The Second Affiliated Hospital of Xi'an Jiaotong University, Xi'an, 710004, Shaanxi Province, People's Republic of \\ China, Tel/Fax +86-29-8767930I, Email zhangyanfei723@I63.com
}

\begin{abstract}
Purpose: Scabies is a common, neglected, and a major health concern skin disease in the world. Improper care may produce a series of complications and even lead to the spread of diseases. Nursing students, as future health-care workers, are vital to the prevention and care of diseases. However, to date, few studies have focused on the basis of their disease cognition for scabies. This study aims to evaluate the level of undergraduate nursing students' awareness of scabies disease.

Methods: A questionnaire survey was conducted among all undergraduate nursing students in Xi'an FanYi University, Xian, Shaanxi Province, China.

Results: All the 132 undergraduate nursing students completed the questionnaire. The true ignorance rate of scabies in this survey was $82.6 \%$. However, among the 56 students $(42.4 \%$ of total) who thought they knew about the disease. Only 23 students $(17.4 \%$ of the samples) had $75 \%$ or more satisfactory knowledge. Fewer students claimed that they had read about the itchy-mite-disease in books $(\mathrm{N}$ $=20,15.2 \%)$. Compared with college textbooks $(P$-value $<0.05)$ and medical books $(P$-value $<0.05)$, other books (medical journals $)$ provide more information about scabies. Nearly half of the students did not know that the scabies can be contagious. All students expressed their willingness to learn about scabies knowledge and participate in the diagnosis and treatment of scabies (100\%).

Conclusion: This study shows that undergraduate nursing students have a poor level of knowledge about scabies. There is an urgent need to improve nursing students' awareness of scabies and increase their knowledge base, so as to strengthen the standardized nursing of scabies and reduce the prevalence of scabies.
\end{abstract}

Keywords: scabies, knowledge, nursing education, nursing students, healthcare

\section{Introduction}

Scabies is a common, neglected skin disease in the world, especially in the developing countries, it is a major health concern. ${ }^{1}$ The annual prevalence of scabies is estimated 300 million world-wide. ${ }^{2}$ It is spread by mites of the Sarcoptidae family through direct close contact, or sometimes indirectly through contaminated fomites such as clothing or quilts. ${ }^{3}$ Compared with the significant impact of the disease on a global scale, the public has much less knowledge and attention to the disease. It mainly affects areas with thin stratum corneum and few hair follicles, with typical skin involvement areas, such as finger joints, wrists, elbows, shoulders, male scrotum, female breasts, etc. The face, head, and neck are rarely affected in adults. It is usually manifested as intense itching and erythematous papules eruption. There are few obvious cavities in the external genital area, and itchy papules are more common. Excoriation due to scratching and parasite-induced inhibition of the local immune response can lead to secondary bacterial infection. The risks of impaired renal function and rheumatic heart disease in scabies patients are higher, infection of skin, soft tissue (including necrotising fasciitis), joints and lower respiratory tract (group A streptococcus, GAS) are also higher. ${ }^{4}$ In addition, due to intense itching at night, the patient's sleep and quality of life are poor. ${ }^{5}$ Scabies outbreaks in residential and nursing care homes for elderly people are more common, due to delayed diagnosis and 
irregular care measures. ${ }^{6}$ So, scabies accounts for a significant global health burden. Nursing students are those who have received professional education and should understand the basic knowledge, diagnosis and treatment of scabies. In this study, we assessed the level of awareness of Chinese nursing students on scabies.

\section{Materials and Methods}

\section{Sample and Setting}

Data was collected using an online self-reported questionnaire. This study included all 132 undergraduate nursing students from the Xi'an FanYi University, located in the Xian, Shaanxi province, China. All students were voluntarily participated in this study and written informed consent was obtained. In order to ensure the number of samples, we used two phase sampling method for no responders. This study was approved by the Institutional Review Board of the Xi'an FanYi University, and performed according to guidelines governing ethics care in China. This study was performed in accordance with the rules laid down in the Declaration of Helsinki and its later amendments.

\section{Data Collection}

The questionnaire was designed in three parts.

The first part was about the students information including age, sex, residential area.

The second part seeks to know the source of the individual's knowledge about scabies and included the following questions:

1. Do your parents or friends worked in the medical field.

2. Do the source of scabies knowledge come from parent(s), newspaper(s), book(s), Internet, doctor(s), friend(s) or radio.

3. Do the book source of scabies knowledge come from junior middle school health textbook(s), high school health textbook(s), university health textbook(s), medical book(s), medical science book(s) or others (such as medical journals).

4. Do you have a history of scabies.

5. Do the family members or friends have a history of scabies.

6. Will you to accept scabies knowledge and participate in the diagnosis and treatment of scabies.

The third part of the questionnaire to determine the basic knowledge and transmission route of scabies, the questions as follows:

1. Pathogeny of scabies.

2. Do the scabies can spread from one person to another.

3. Do the scabies can spread by clothes sharing.

4. Do the scabies can spread by handshake.

5. Do the scabies can transmitted through touching patients' personal items.

6. Do the scabies can spread by public bedding.

7. Do the scabies can spread by sexual contact.

8. Where the lesions site(s) for adults is/are prone to be at, the finger webs, wrist, cubital fossa, axilla, trunk, genitalia, inner thighs or head and face.

9. Do the characteristics of scabies itch are mild during the day and severe at night or severe during the day and mild at night.

10. Do the clinical features of scabies lesions are scaly erythema and/or papules and vesicles.

11. Do you know about "scabies nodule".

12. Do the scabies nodules are located at the male external genitalia. 


\section{Data Analysis}

The data was analyzed using the SPSS software package (SPSS 19.0). The results were presented as the mean \pm SD scores. Single variable analyses were performed with nonparametric methods for 2-group (Mann-Whitney $U$-test) and multiple-group (Kruskal-Wallis test) comparisons. Chi square goodness-of-fit tests and Pearson's Chi square tests to check for independence of categorical variables were performed. Two-tailed t-tests for significance were utilized and a $p$-value of less than 0.05 was considered as statistically significant.

\section{Results}

\section{Characteristics of the Participants and the Level of Scabies Knowledge}

All 132 undergraduate nursing students completed the questionnaire, including 15 male and 117 female. Most students are from the rural area $(\mathrm{N}=75)$, the others come from the urban area $(\mathrm{N}=52)$ and suburban $(\mathrm{N}=5)$. As shown in Table 1, a few students had a history of scabies $(\mathrm{N}=21,15.9 \%)$ compared to those without the history $(\mathrm{N}=111,84.1 \%)$. Regarding the question about whether your parents or friends worked in the medical field, 71 students answered yes and 61 answered no. 56 students ( $42.4 \%$ of total) were confident in their knowledge of scabies, and 20 of them (35.7\%) had parents or friends working in the medical field and had a scabies history. On the other hand, individuals with no confidence of their knowledge about the scabies have no parents or friends working in the medical field, and no relevant scabies history $(\mathrm{N}=75,98.7 \%)$. Most of the students did not know the pathogeny of scabies. However, of the 56 students (42.4\% of total) who thought they knew the disease, only 23 (41.1\% of those, $17.4 \%$ of total) actually wrote down the correct answer. Therefore, the true ignorance rate of scabies revealed in this survey was $82.6 \%(\mathrm{~N}=109)$. There is a significant correlation between the cognition of individuals who think they know about scabies and those who do not know and their actual knowledge about the disease $(P$-value $<0.001)$. It has been seen that students who are confident in their knowledge of scabies have a higher level of actual knowledge of the disease. In this survey, the students had a higher rate of ignorance about scabies, but all expressed their willingness to learn about scabies and participate in the diagnosis and treatment of scabies $(\mathrm{N}=132,100 \%)$.

\section{Influence of History of Scabies in an Individual or Family Members or Friends on Scabies Knowledge}

The history of scabies in an individual significantly affects his/her knowledge about scabies $(P$-value $<0.05)$. Students had a history of scabies showed a better understanding of this disease. Similarly, a past experience of scabies in family members or friends significantly also affects his or her knowledge of scabies $(P$-value $<0.001)$. Significant difference in levels of scabies knowledge between students who have parents or friends work in the medical field and no one $(P$-value $=0.045)$.

\section{Analysis of Scabies Knowledge Scores}

The mean percentage scabies knowledge scores was $23.88 \pm 28.88 \%$, ranging from a minimum of $0 \%$ ( 76 scored a total of $0 \%$, accounting for $57.6 \%$ of the total population) to a maximum of $100 \%$ (10 people scored $100 \%$, accounting for $7.6 \%$ of the total population). Indeed, when the percentage knowledge was organized into categories, the inequality of the distribution was significant ( $P$-value $<0.001$ ). If a total percentage score above $75 \%$ was taken as a criterion of satisfactory awareness, then only 23 individuals ( $17.4 \%$ of the total samples) had satisfactory awareness. There was no difference in levels of scabies knowledge among students from different residential areas $(P$-value $=0.615)$.

Table I Characteristics of the Participants

\begin{tabular}{|l|c|c|}
\hline & Yes N, \% & No N, \% \\
\hline Parent(s)/friend(s) worked in the medical field & $71,(53.8 \%)$ & $61,(46.2 \%)$ \\
Confident about knowledge of scabies & $56,(42.4 \%)$ & $76,(57.6 \%)$ \\
History of scabies & $21,(15.9 \%)$ & $111,(84.1 \%)$ \\
\hline
\end{tabular}


Table 2 Frequency of Different Sources Which Came from Scabies Knowledge

\begin{tabular}{|l|c|c|}
\hline & Observed, N & Percentage (\%) \\
\hline No answer & 76 & 57.6 \\
Friends only & 3 & 2.3 \\
Radio or television only & 2 & 1.5 \\
Internet only & 14 & 10.6 \\
Doctor only & 3 & 2.3 \\
Books only & 20 & 15.1 \\
Parents only & 2 & 1.5 \\
Newspaper only & 1 & 0.8 \\
2 different sources & 4 & 3.0 \\
3 different sources & 3 & 2.3 \\
4 different sources & 2 & 1.5 \\
5 different sources & 2 & 1.5 \\
\hline
\end{tabular}

Table 3 Frequency at Which Different Books Were Read

\begin{tabular}{|l|c|c|}
\hline & Observed, N & Percentage (\%) \\
\hline Other books (such as medical journals) & 8 & 40.0 \\
Medical science books & 3 & 15.0 \\
Medical books & 4 & 20.0 \\
University health textbooks & 3 & 15.0 \\
Junior middle school health textbooks & 1 & 5.0 \\
High school health textbooks & 1 & 5.0 \\
Total & 20 & 100.0 \\
\hline
\end{tabular}

\section{Sources of Scabies Knowledge}

Only 20 students had ever read about scrapie mite in books $(\mathrm{N}=20,15.2 \%)$, and the proportion of students who had never read it was higher $(\mathrm{N}=112,84.8 \%)$. There is a significant correlation between the scabies percentage knowledge and the type of book from which information is obtained $(P$-value $<0.01)$. Other books provided more scabies knowledge than university health textbook $(P$-value $<0.05)$ and medical books $(P$-value $<0.05)$. Among the university health textbooks, textbooks of dermatology and venereology were the primary source of scabies knowledge. There was a significant association between the percentage knowledge and the diverse sources from which students read or hear about scabies $(P$-value $<0.001)$ (see Tables 2 and 3). Doctors, books and Internet were seen to provide the best source of information compared to others.

\section{Analysis of Awareness Rate About Clinical Manifestation and Transmission of Scabies} Around $50 \%$ of students did not know the details of spread of scabies. Table 4 gives the details of the answers to these questions. Among the positive responses obtained about the clinical manifestations of the disease, only a few students gave multiple correct answers $(\mathrm{N}=40,30.3 \%$ of total). For the single answer, finger webs topped the list $(\mathrm{N}=24$, $18.2 \%)$, followed by inner thighs $(\mathrm{N}=19,14.4 \%)$, then trunk $(\mathrm{N}=15,11.4 \%)$, axilla $(\mathrm{N}=10,7.6 \%)$, head and face $(\mathrm{N}=$ $7,5.3 \%)$, genitalia $(\mathrm{N}=6,4.5 \%)$, wrist flexor $(\mathrm{N}=3,2.3 \%)$ and cubital fossa $(\mathrm{N}=2,1.5 \%)$. Again, most of the students preferred not to choose any clinical presentation of the disease $(\mathrm{N}=80,60.6 \%), 18(13.6 \%)$ answered that the lesions are scaly erythema, and $34(25.8 \%)$ chose papules and vesicles. About one-third of the students $(\mathrm{N}=44,33.3 \%)$ reported that the itching in scabies is mild during the day and severe at night. A small number $(\mathrm{N}=12,9.1 \%)$ reported the contrary, and $76(57.6 \%)$ did not know any more about this question. The majority of students involved in this study did not know about the scabies nodule $(\mathrm{N}=89,67.4 \%)$. Of the $43(32.6 \%)$ students who wrote that they know about scabies 
Table 4 Frequency of Responses Obtained to Questions About Spread of Scabies

\begin{tabular}{|l|c|c|}
\hline \multirow{2}{*}{ Questions } & \multicolumn{2}{|c|}{ Frequency of Responses Obtained, N (\%) } \\
\cline { 2 - 3 } & Yes & No \\
\hline Do the scabies can spread from one person to another & $64,(48.5 \%)$ & $57,(51.5 \%)$ \\
Do the scabies can spread by clothes sharing & $75,(56.8 \%)$ & $86,(65.2 \%)$ \\
Do the scabies can spread by handshake & $46,(34.8 \%)$ & $56,(42.4 \%)$ \\
Do the scabies can spread through touching patients' personal items & $76,(57.6 \%)$ & $51,(38.6 \%)$ \\
Do the scabies can spread by public bedding & $81,(61.4 \%)$ & $77,(58.3 \%)$ \\
Do the scabies can spread by sexual contact & $55,(41.7 \%)$ & \\
\hline
\end{tabular}

nodule, and 39 (90.7\%) knew it appeared in the external genitalia. Total 93 (70.5\%) students in this sample did not know that the scabies nodule can be found at the male genitalia.

\section{Discussion}

Scabies is a global scourge, especially in developing countries. It brings a heavy burden to the health-care system and it has been suggested to be a highly neglected tropical disease. ${ }^{1,7}$ Delays in disease recognition, treatment and prevention can blow this innocent skin infection out of proportion. The longer a patient carries the mites within his/her skin, the higher the risk of severe secondary complications occurring, ${ }^{8}$ such as rheumatic heart disease and impaired renal function. ${ }^{9,10}$ Increasing health issues translate into a shooting financial burden. Although there are many treatment options available, scabies is still epidemics, especially in resource poor areas. ${ }^{2}$

In nursing care homes for the elderly people, there are often scabies outbreaks that are delayed in diagnosis and difficult to control. These outbreaks are often difficult to identify and manage, leading to long delays in identification and control, and substantial costs. ${ }^{11,12}$ The burden of scabies in low-income and middle-income countries is much greater. Health-care workers expect the nurse should be aware of the presentation of scabies in elderly and should do thorough examinations, especially if patients are asymptomatic. ${ }^{6,13}$ However, to date, few studies have focused on the basis of their disease cognition for scabies.

The International Alliance for the Control of Scabies (IACS) developed a global control plan in order to improve the health of affected communities worldwide. ${ }^{14}$ Epidemiology education for staff in the institution is the key to maximising the effectiveness of treatment and control measures, in order to prevent spread of the disease. ${ }^{15-17}$ The greatest DALYs of scabies are in tropical regions in East Asia (China (including Taiwan), North Korea), and it is a contagious skin disease. ${ }^{2,18}$ Our study found medical books, medical journals and medical science books were the largest amount of information. Nursing students are encouraged to read books concerning medical sciences and medical information in the Internet, because this study shows that these are the best ways to provide correct data. This study highlights the surprisingly insufficient level of knowledge among nursing students about scabies infection. As many as half of the study subjects were unable to correctly answer any questions about this disease. Although approximately $50.2 \%$ of people agreed that this infection can be spread from one person to another through sharing clothes, shaking hands, touching patients' personal items, sharing bedding, and sex. Less than $18 \%$ of students had a satisfactory scabies knowledge taken as $75 \%$ and above.

A very significant aspect of scabies prevention is the degree of medical practitioners understanding it. This study has revealed a very low level of knowledge about the scabies in nursing students. Nursing students who are ignorant about its cause are unaware that they are skin-eating-parasites dwelling in the epidermis that can be killed. They know little, if any, about the disease spread and/or its methods. Failure of preventive measures has become a permissive factor in the spread of scabies, contributing to an increase in the burden of disease, and paving the way for the development of epidemic. Delay in recognition of the clinical features of this itchy-skin-pathology leads to a persistently high incidence of scabies and its complications due to a lack of treatment. Schools should be the starting points of health education programs. At a tender age, students, especially nursing students are more receptive to information. 


\section{Conclusion}

In summary, this study found that nursing students have a low level of knowledge about scabies. It is suggested that relevant health departments should actively carry out disease and health education programs for nursing students. In addition, the current study was conducted with a small sample size. In the future, a larger sample size is needed, including students from different schools in different regions.

\section{Funding}

There is no funding to report.

\section{Disclosure}

The authors declare that they have no conflicts of interest to this work.

\section{References}

1. Leung AKC, Lam JM, Leong KF. Scabies: a neglected global disease. Curr Pediatr Rev. 2020;16(1):33-42. doi:10.2174/ 1573396315666190717114131

2. Chosidow O. Clinical practices. Scabies. N Engl J Med. 2006;354(16):1718-1727. doi:10.1056/NEJMcp052784

3. Fuller LC. Epidemiology of scabies. Curr Opin Infect Dis. 2013;26(2):123-126. doi:10.1097/QCO.0b013e32835eb851

4. Karimkhani C, Colombara DV, Drucker AM, et al. The global burden of scabies: a cross-sectional analysis from the Global Burden of Disease Study 2015. Lancet Infect Dis. 2017;17(12):1247-1254. doi:10.1016/S1473-3099(17)30483-8

5. Jingang A, Shengxiang X, Shengbin X, et al. Quality of life of patients with scabies. J Eur Acad Dermatol Venereol. 2010;24(10):1187-1191. doi:10.1111/j.1468-3083.2010.03618.x

6. Morrison EJ, Middleton J, Lanza S, et al. Do we know how scabies outbreaks in residential and nursing care homes for the elderly should be managed? A systematic review of interventions using a novel approach to assess evidence quality. Epidemiol Infect. 2019;147:e250. doi:10.1017/ S0950268819001249

7. Heukelbach J, Feldmeier H. Scabies. Lancet. 2006;367(9524):1767-1774. doi:10.1016/S0140-6736(06)68772-2

8. Hengge UR, Currie BJ, Jäger G, Lupi O, Schwartz RA. Scabies: a ubiquitous neglected skin disease. Lancet Infect Dis. 2006;6(12):769-779. doi:10.1016/S1473-3099(06)70654-5

9. Swe PM, Reynolds SL, Fischer K. Parasitic scabies mites and associated bacteria joining forces against host complement defence. Parasite Immunol. 2014;36(11):585-593. doi:10.1111/pim.12133

10. Chung SD, Wang KH, Huang CC, Lin HC. Scabies increased the risk of chronic kidney disease: a 5-year follow-up study. J Eur Acad Dermatol Venereol. 2014;28(3):286-292. doi:10.1111/jdv.12099

11. Engelman D, Steer AC. Diagnosis, treatment, and control of scabies: can we do better? Lancet Infect Dis. 2018;18(8):822-823. doi:10.1016/S14733099(18)30372-4

12. Cassell JA, Middleton J, Nalabanda A, et al. Scabies outbreaks in ten care homes for elderly people: a prospective study of clinical features, epidemiology, and treatment outcomes. Lancet Infect Dis. 2108;18(8):894-902. doi:10.1016/S1473-3099(18)30347-5

13. Hewitt KA, Nalabanda A, Cassell JA. Scabies outbreaks in residential care homes: factors associated with late recognition, burden and impact. A mixed methods study in England. Epidemiol Infect. 2015;143(7):1542-1551. doi:10.1017/S0950268814002143

14. Engelman D, Kiang K, Chosidow O, et al. Toward the global control of human scabies: introducing the international alliance for the control of scabies. PLoS Negl Trop Dis. 2013;7(8):e2167. doi:10.1371/journal.pntd.0002167

15. Chandler DJ, Fuller LC. A review of scabies: an infestation more than skin deep. Dermatology. 2019;235(2):79-90. doi:10.1159/000495290

16. Engelman D, Cantey PT, Marks M, et al. The public health control of scabies: priorities for research and action. Lancet. 2019;394(10192):81-92. doi:10.1016/S0140-6736(19)31136-5

17. Salavastru CM, Chosidow O, Boffa MJ, Janier M, Tiplica GS. European guideline for the management of scabies. J Eur Acad Dermatol Venereol. 2017;31(8):1248-1253. doi:10.1111/jdv.14351

18. Tarbox M, Walker K, Tan M. Scabies. JAMA. 2018;320(6):612. doi:10.1001/jama.2018.7480

Clinical, Cosmetic and Investigational Dermatology

\section{Dovepress}

\section{Publish your work in this journal}

Clinical, Cosmetic and Investigational Dermatology is an international, peer-reviewed, open access, online journal that focuses on the latest clinical and experimental research in all aspects of skin disease and cosmetic interventions. This journal is indexed on CAS. The manuscript management system is completely online and includes a very quick and fair peer-review system, which is all easy to use. Visit http://www. dovepress.com/testimonials.php to read real quotes from published authors.

Submit your manuscript here: https://www.dovepress.com/clinical-cosmetic-and-investigational-dermatology-journal 